\title{
Description of a new Allochthonius species from China, with a key to the genus (Pseudoscorpiones: Pseudotyrannochthoniidae)
}

\author{
Zhizhong Gao \& Feng Zhang*
}

Gao, Z. \& Zhang, F. 2013: Description of a new Allochthonius species from China, with a key to the genus (Pseudoscorpiones: Pseudotyrannochthoniidae). - Entomol. Fennica 23: 107-112.

A new pseudoscorpion species, Allochthonius exornatus sp. n., belonging to the family Pseudotyrannochthoniidae Beier, 1932, is described from China. Detailed diagnosis, descriptions and illustrations are presented, and a key to the genus Allochthonius Chamberlin, 1929 is provided.

Z. Gao \& F. Zhang (*Corresponding author), College of Life Sciences, Hebei University, Baoding, Hebei 071002, China; E-mails: gaozhizhong1987 @126.com, *Corresponding author:dudu06042001@163.com

Received 2 November 2012, accepted 3 January 2013

\section{Introduction}

The pseudoscorpion family Pseudotyrannochthoniidae Beier, 1932 contains five genera, Afrochthonius Beier, Allochthonius Chamberlin, Centrochthonius Beier, Pseudotyrannochthonius Beier and Selachochthonius Chamberlin (Harvey 2011). Two of them, Allochthonius and Centrochthonius, have been reported from China (Schawaller 1995), and later the species Centrochthonius sichuanensis Schawaller, 1995 was transferred to Allochthonius (Hu \& Zhang 2011).

The genus Allochthonius was erected by Chamberlin (1929) for the type species Chthonius opticus Ellingsen, 1907 from Japan through an original designation. Presently, the genus Allochthonius is divided into two subgenera, Allochthonius and Urochthonius Morikawa, 1954, based on the presence or absence of eyes. Their species are widely distributed in Japan and South Korea. The subgenus Allochthonius is composed of twelve species mainly distributed in East Asia (Japan, South Korea, North Korea and
China) of which five occur in China. The subgenus Urochthonius includes three species (Harvey 2011, Hu \& Zhang 2012) of which two occur in Japan and the third was reported from western China.

While examining pseudoscorpion specimens collected during summer 2012 in northern China, we found a new Allochthonius species belonging to the subgenus Allochthonius, which is described and illustrated in this paper under the name $A$. (A.) exornatus sp. n. A key to the species of the genus Allochthonius is also provided.

\section{Material and methods}

The specimens are preserved in $75 \%$ alcohol and deposited in the Museum of Hebei University (MHBU), Baoding City, China.

Microscopic examination and drawings were carried out with a Leica M165c stereomicroscope with a drawing tube. Photographs were taken with a Leica M205a stereomicroscope, which 


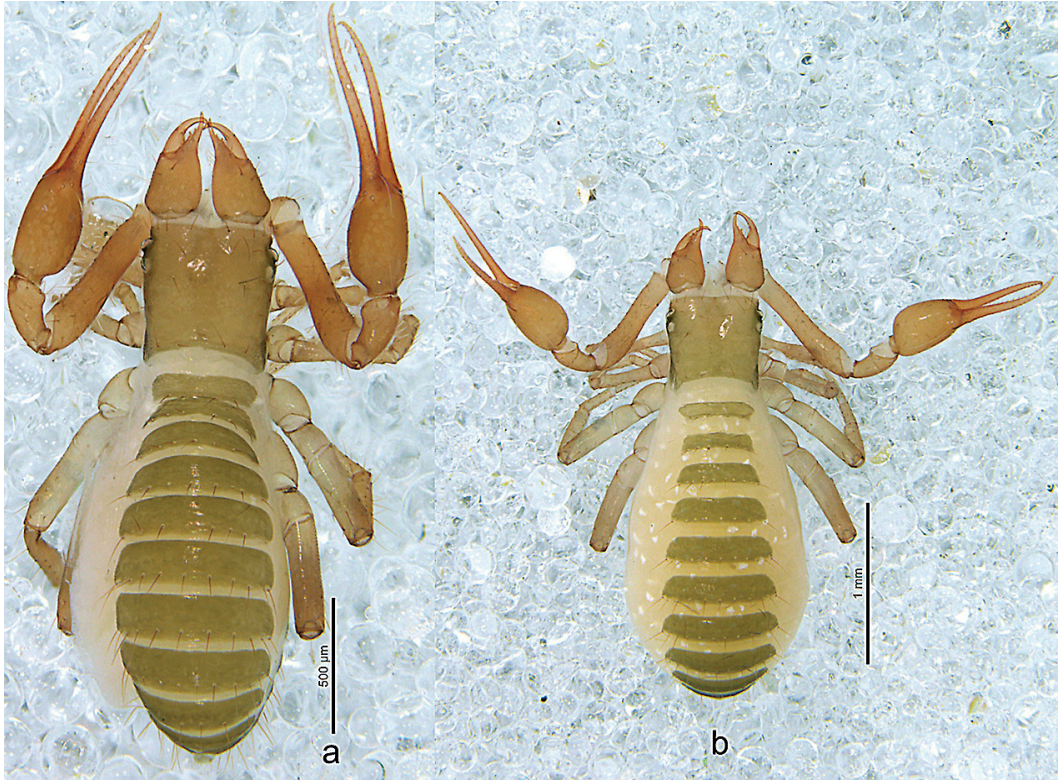

Fig. 1. Allochthonius (Allochthonius) exornatus sp. n. - a. Habitus, dorsal view of holotype. - b. Habitus, dorsal view of female paratype (Ps.-MHBUJ112073002). was also used for the measurements. Detailed examination was carried out with an Olympus BX53 general optical microscope. Temporary slide mounts were made in glycerol.

The term "rallum" (for flagellum) follows Judson (2007). The pattern of description and terminology follow Chamberlin (1931) and Harvey (1992). The setal formula of the palp femur follows Vachon (1941) and that of leg femur are taken using Judson's (2007) reference points. The chela and chelal hand are measured in lateral view and all measurements are given in mm. 10-6-42-4 (26) refers to carapacal chaetotaxy: carapace with 26 setae, anterior margin with ten setae and posterior margin with four setae.

\section{Description of Allochthonius (Allochthonius) exornatus sp. $\mathbf{n}$. (Figs 1-3)}

Subgenus Allochthonius (Allochthonius) Chamberlin, 1929

Beier, 1932: 61-62; Morikawa, 1960: 98; Harvey, 1991: 132; Hu \& Zhang, 2011: 21682169; Hu \& Zhang, 2012: 243-248.

Type material. Holotype male (Ps.-MHBUJ120730): China: Hebei Province, Zhuolu County, Xiaowutai Mountain National Nature
Reserve [39 $51^{\prime} \mathrm{N}, 114^{\circ} 52^{\prime} \mathrm{E}$ ], a.s.1. 1,351 m, 30.VII.2012, leg. Feng Zhang. Paratypes: 1 male (Ps.-MHBU-JI12073001) and 2 females (Ps.MHBU-JI12073002-12073003), same data as for holotype.

Diagnosis. This species is characterized by the lateral surface on chelal hand possessing rounded whitish patches and the shape and number of seven coxal spines present on coxae I, each blade having a central spine terminally that is distinctly expanded into a fan-shaped structure, all situated on a common tubercle.

This species differs from the other members of the subgenus Allochthonius in having ornamented surface on the chelal hand which is unique. The new species is closely similar to Allochthonius (A.) liaoningensis from China in having the same carapacal formula, four eyes, similar body length, chelicerae with 5 to 6 setae and they were both collected from North China. The new species can be easily distinguished from A. (A.) liaoningensis by its smaller size (e.g. chela length $1.0-1.12 \mathrm{~mm}$ (male) vs. $1.28-1.30 \mathrm{~mm}$ ), by the presence of straight teeth on the chelal movable finger (vs. teeth retrorse in liaoningensis) and by the number of the coxal spines (6-7 vs. 8 in liaoningensis).

Description. Body (Fig. 1) light yellowish brown, chelicerae and palps reddish brown.

Carapace (Fig. 2a) subquadrate, slightly lon- 
Fig. 2. Allochthonius (Allochthonius) exornatus sp. n., holotype. - a. Carapace (dorsal view). - b. Left chelicerae (dorsal view). -c. Coxal spines on leg I (ventral view). - d. Rallum. - e. Left palp (minus chela, dorsal view). - f. Left chela (lateral view). $-\mathrm{g}$. Tip of palpal fingers (dorsal view). - h. Left leg I (lateral view). - i. Genital area (ventral view). -j. Left leg IV (lateral view). Scale bars: 0.10 $\mathrm{mm}(\mathrm{b}-\mathrm{d}, \mathrm{g}), 0.20 \mathrm{~mm}$ $(a, e-f, h-j)$.
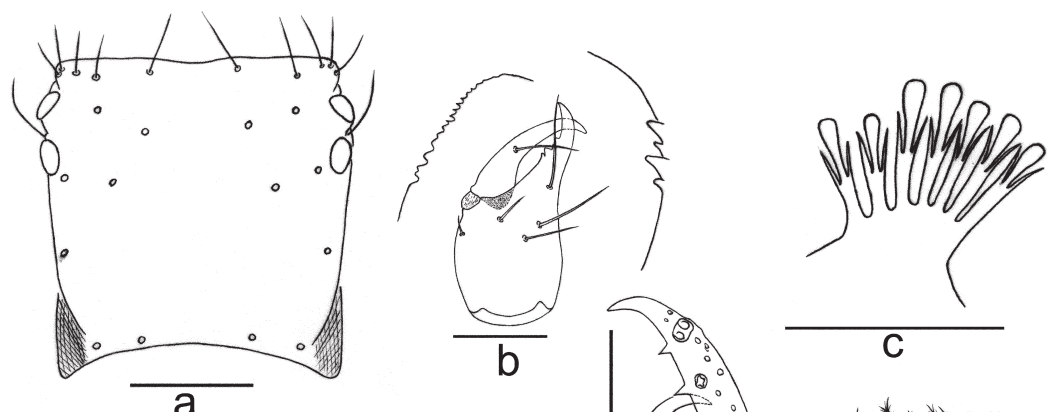

a

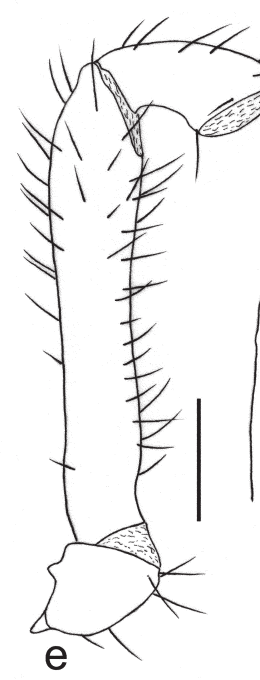

b
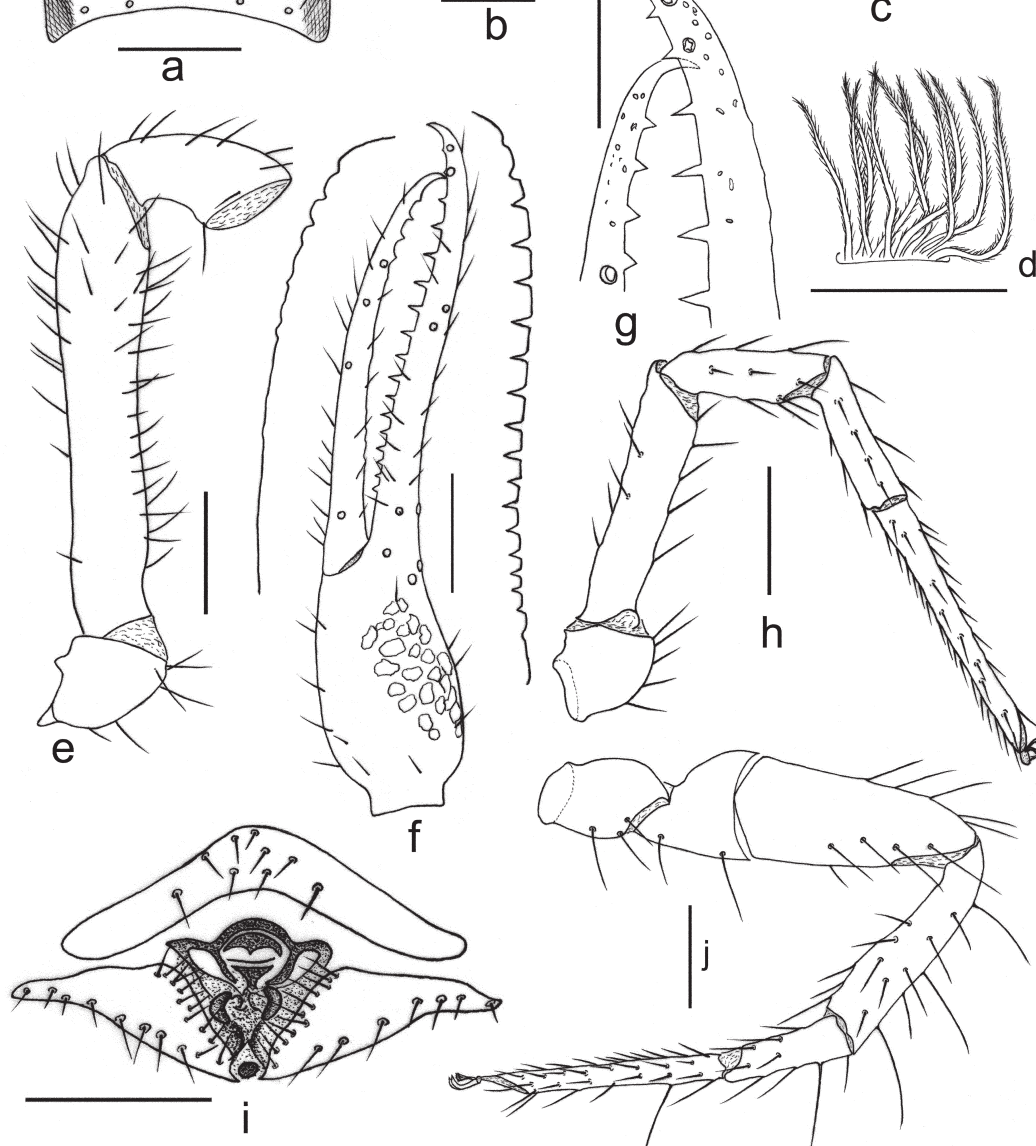

d

$\mathrm{g}$<smiles>C1CCC1</smiles>

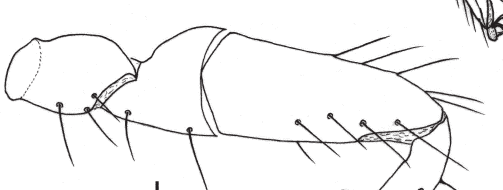

ger than broad (1.02-1.04 times) in males and slightly shorter than broad in females (0.96-0.98 times), carapace slightly constricted posteriorly; anterior eyes with well-developed tapeta and situated on tubercles, posterior eyes with less developed tapeta than anterior eyes and not situated on tubercles; without epistome, space between median setae straight or slightly recurved; chaetotaxy 10-6-4-2-4 (26).

Male tergal chaetotaxy (including male holotype and the paratype) I-X:4: 6: 7-8: 7-8: 810:11: 11-12: 12: 8-9: 5:TT: 0; anterior genital

operculum (Fig. 2i) with 8-9 setae, genital opening pit-like in the basal half, 7-8 marginal setae on each side; sternal chaetotaxy III-X: 11-16: 17: 15-16: 15-16: 15-16: 16-17: 11-13: 9: 2; coxae typical, setae P5, I 4, II 5, III 6, IV 7; inter coxal tubercle present and with two setae. Female tergal chaetotaxy I-X: 4-5: 6-7: 6-10: 8-9: 10-11:11: 11-12: 10-12: 7-10: 6: 2; anterior genital operculum with 13-14 setae, posterior margin with 23-26 marginal setae; sterna chaetotaxy IVX: 17-19: 15-16: 14-16: 16: 15: 12: 8-10: 2; setae P 5, I 3, II 5, III 6, IV 6. Coxae I each with 7- 


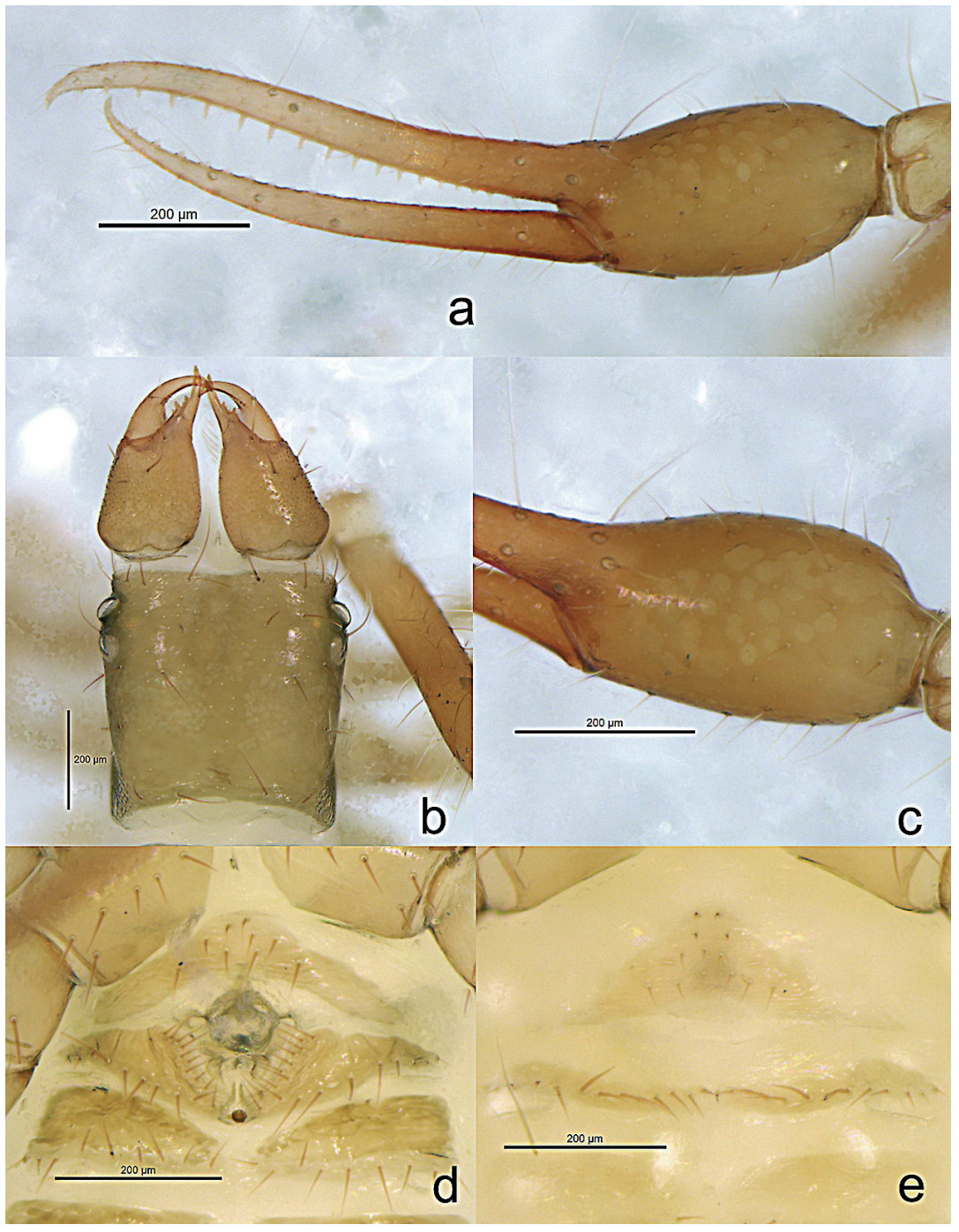

Fig.3. Allochthonius (Allochthonius) exornatus sp. n. - a. Left chela of holotype. -b. Carapace and chelicerae of holotype. - c. Left chelal hand of holotype. - d. Genital area of holotype. - e. Genital area of female paratype (Ps.MHBU-JI12073002).
8 spines, arranged on a common tubercle (Fig. 2c).

Cheliceral (Fig. 2b) palm with 6 setae, of which a short one located laterally; palm with tiny granulation. Fixed finger with four teeth, of which sub-basal and apical tooth large and other two small; movable finger with 15 relatively small acute teeth, gradually enlarging from terminal half to basal half; spinneret absent. Serrula exterior with 14-15 lamellae, serrula interior with 13-14 lamellae. Rallum in two rows and composed of 10 blades with fine barbules, of which posterior blade shorter than others, very anterior one longest.

Palp (Figs 2e-g) smooth with lateral surface of hand possessing rounded whitish patches; femur 1.49-1.56 times longer than carapace, setal formula3-6-8-2-12-5; chelal finger straight in dorsal view; fixed finger with 18 acute teeth, in middle larger than that in both ends; movable finger with 5-7 irregular acute teeth in terminal half, all of which different in size; sensilla absent.

Legs (Figs 2h, j) typical. Femur of leg I 1.611.67 times longer than patella, tarsus 2.00-2.10 times longer than tibia, setae of leg I (trochanter to tibia) 6: 17: 14: 17, setae of leg IV (trochanter to metatarsus) 3: 2: 11: 19: 20; patellae of legs III and IV each with 4 setae in dorsal row; femur III and IV without dorsal setae; trochanter II with 5 setae, trochanter III with 6 setae. Leg IV with 2 
tactile setae, one on metatarsus $(\mathrm{TS}=0.21)$ and another on tarsus (TS $=0.17)$, TS showing location of tactile seta as ratio of $\mathrm{a} / \mathrm{b}$, where $\mathrm{a}=$ distance of seta from proximal joint and $b=$ length of leg segment.

Measurements. Males, holotype and paratype (length $\times$ width in $\mathrm{mm}$, ratio in parentheses). Body length $1.84-1.93$. Carapace $0.47-0.50 \times 0.45-$ 0.49 (1.02-1.04). Chelicera $0.40-0.42 \times 0.20$ 0.21 (2.00), movable finger length $0.23-0.24$. Palpal trochanter $0.19-0.21 \times 0.13-0.14(1.46-$ $1.50)$, femur $0.70-0.78 \times 0.13-0.14(5.38-5.57)$, patella $0.24-0.28 \times 0.12-0.14(2.00)$, chela $1.02-$ $1.12 \times 0.20-0.22(5.09-5.10)$, chelal hand length $0.35-0.37$ (1.68-1.75), movable finger length $0.64-0.68$ (1.83-1.84× hand). Leg I femur 0.37$0.40 \times 0.08(4.63-5.00)$, patella $0.23-0.24 \times 0.08$ (2.88-3.00), tibia $0.20-0.22 \times 0.05-0.06(3.67-$ $4.00)$, tarsus $0.42-0.44 \times 0.05(8.40-8.80)$; leg IV femur+patella $0.57-0.63 \times 0.19-0.21(3.00)$, tibia $0.41-0.46 \times 0.09-0.10 \quad(4.56-4.60)$, metatarsus $0.23-0.24 \times 0.07 \quad(3.29-3.43)$, tarsus $0.44-$ $0.47 \times 0.05(8.80-9.40)$.

Brief description of female paratypes. Mostly same as holotype, Body length 1.89-2.51. Carapace $\quad 0.51-0.55 \times 0.53-0.56 \quad(0.96-0.98)$. Chelicera $0.48-0.50 \times 0.24-0.25$ (2.00), movable finger length $0.29-0.30$. Palpal trochanter $0.23 \times 0.14-0.15 \quad(1.53-1.64)$, femur $0.83-$ $0.87 \times 0.15-0.16 \quad(5.44-5.53)$, patella $0.32-$ $0.33 \times 0.14-0.16 \quad(2.00-2.36)$, chela $1.18-$ $1.25 \times 0.26-0.29(4.31-4.54)$, chelal hand length $0.39-0.46$ (1.50-1.59), movable finger length $0.74-0.80$ (1.74-1.90× hand). Leg I femur 0.42$0.44 \times 0.09(4.67-4.89)$, patella $0.25-0.27 \times 0.08-$ 0.09 (3.00-3.13), tibia $0.23-0.24 \times 0.07$ (3.29$3.43)$, tarsus $0.47-0.49 \times 0.06(7.83-8.17)$; leg IV femur+patella $\quad 0.66-0.70 \times 0.21-0.23 \quad(3.04-$ 3.14 ), tibia $0.48-0.52 \times 0.10-0.11(4.73-4.80)$, metatarsus $0.26-0.27 \times 0.07(3.71-3.86)$, tarsus $0.48-0.51 \times 0.05(9.60-10.20)$.

Distribution. China (Hebei).

Etymology. The specific name is derived from the Latin word "exornatus" meaning embellished, referring to the lateral surface of chelal hand possessing rounded whitish patches.

\section{Key to species of the genus Allochthonius}

1. Eyes absent (rarely two eyes) (Subgenus Urochthonius) 2

- Four developed eyes (Allochthonius s.str.) 4

2. Palpal femora stouter, less than 5 times as long as broad Allochthonius (U.) brevitus

- Palpal femora slender, more than 5 times as long as broad

3. Two elevated and vestigial eyes Allochthonius (U.) biocularis

- Eyes absent Allochthonius (U.) ishikawai

4. Teeth on the chelal movable finger retrorse Allochthonius (A.) liaoningensis

- Teeth on the chelal movable finger straight 5

5. Cheliceral palm with five setae on dorsal surface, one seta on ventral surface

Allochthonius (A.) buanensis

- Cheliceral palm with five or six setae on dorsal surface, without any seta on ventral surface

6

6. Epistome present 7

- Epistome absent 8

7. Cheliceral palm with six setae; fixed finger of chela with 30 teeth, movable finger with 25 teeth Allochthonius (A.) coreanus

- Cheliceral palm with five setae; fixed finger of chela with 18 to 20 teeth, movable finger with eight to nine acute spaced teeth on the apical half and nine to ten reduced or vestigial teeth on the basal half

Allochthonius (A.) borealis

8. Each coxal spine clavate 9

- Each coxal spine with tridentate branches and the central one terminally spatulate or expanded as fan-shaped 10

9. Fixed finger of chelicera with a very large posterior tooth, the others smaller and of equal length Allochthonius (A.) opticus

- Fixed finger of chelicera with a large anterior and nearly equal-sized posterior tooth, with two or three smaller intervening ones Allochthonius (A.) shintoisticus

10. Number of carapacal setae at least $26 \quad 11$

- Number of carapacal setae notmore than 26

11. Anterior margin of carapace with protuberances

Allochthonius (A.) trigonus 
- Anterior margin of carapace without protuberances

12. Lateral surface of chelal hand ornamented with rounded whitish patches Allochthonius (A.) exornatus sp.n.

- Lateral surface of chelal hand without any ornamentation Allochthonius (A.) sichuanensis

13. Each coxal spine with tridentate branches and the central one terminally spatulate

- Each coxal spine with tridentate branches and the central one terminally expanded as fanshaped

14. Carapacal chaetotaxy 8 (or 9 or 10)-4-4-2-4, 22 (or 23 or 24); fixed finger of chelicerae with four or five (rarely three) conspicuous marginal teeth, movable finger with about 12 to 16 fine denticulations

\section{Allochthonius (A.) tamurai}

- Carapacal chaetotaxy 6-4-2-2-4, 18; fixed finger of chelicerae with one large and seven or nine middle or small marginal teeth, movable finger with 16 to 20 fine denticulations

Allochthonius (A.) montanus

15. Color of chelal hand distinctly darker than other segments Allochthonius (A.) fuscus

- Color of all chelal segments nearly the same Allochthonius (A.) wui

Acknowledgements. We are grateful to Dr. Volker Mahnert and Dr. Juan Antonio Zaragoza for kindly reviewing the manuscript. This work was supported by the National Natural Science Foundation of China (No. 31093430, 31071885, 30970325), and by the Ministry of Science and Technology of the People's Republic of China (MOST Grant No. 2012FY110803).

\section{References}

Beier, M. 1932: Pseudoscorpionidea I. Subord. Chthoniinea et Neobisiinea. - Tierreich 57: i-xx, 1-258.

Chamberlin, J. C. 1929: On some false scorpions of the suborder Heterosphyronida (Arachnida - Chelonethida). - Canadian Entomologist 61: 152-155.

Chamberlin, J. C. 1931: The arachnid order Chelonethida. Stanford University Publications. - Biological Sciences 7: 1-284.

Harvey, M. S.1991: Catalogue of the Pseudoscorpionida. - Manchester University Press, Manchester. 726 pp.

Harvey, M. S. 1992: The phylogeny and classification of the Pseudoscorpionida (Chelicerata: Arachnida). Invertebrate Taxonomy 6: 1373-1435.

Harvey, M. S. 2011: Pseudoscorpions of the World, version 2.0. - Western Australian Museum, Perth [www document]. URL http://www.museum.wa.gov.au/catalogues/pseudoscorpions (accessed 30 October 2012).

Hu, J. F. \& Zhang, F. 2011: Description of three new species of the genus Allochthonius Chamberlin, 1929 (Pseudoscorpiones: Pseudotyrannochthoniidae) from China. - Journal of Threatened Taxa 3(11): $2167-$ 2176.

Hu, J. F. \& Zhang, F. 2012: Two new species of the genus Allochthonius Chamberlin from China (Pseudoscorpiones: Pseudotyrannochthoniidae). - Entomologica Fennica 22: 243-248.

Judson, M. L. I. 2007: A new and endangered species of the pseudoscorpion genus Lagynochthonius from a cave in Vietnam, with notes on chelal morphology and the composition of the Tyrannochthoniini (Arachnida, Chelonethi, Chthoniidae). - Zootaxa 1627: 53-68.

Morikawa, K.1960: Systematic studies of Japanese pseudoscorpions. - Memoirs of Ehime University (2B) 4: 85-172.

Schawaller, W. 1995: Review of the speudoscorpion fauna of China (Arachnida: Pseudoscorpionida). - Revue Suisse de Zoologie 102 (4): 1045-1064.

Vachon, M. 1941: Chthonius tetrachelatus P. (Pseudoscorpions) et ses formes immatures (1re note). - Bulletin du Muséum National d'Histoire Naturelle, Paris (2) 13: 442-449. 